\title{
Statistical Measure to Quantify Genetic Purity in a Larger Area with Real-Time Population in Pigeon Pea
}

\author{
Rakesh C. Mathad ${ }^{1 *}$ and A.S. Channaveeraswamy ${ }^{2}$ \\ ${ }^{1}$ Director of Education, UAS, Raichur, India \\ ${ }^{2}$ ARS, Annigeri, India \\ *Corresponding author
}

\section{A B S T R A C T}

\section{Keywords}

Genetic Purity

Confidence Level,

Regression, Pigeon

pea, TS3R, Real

time plant

population,

Variables

\section{Article Info}

Accepted:

18 August 2020

Available Online:

10 September 2020
The need to quantify genetic purity in a larger area with real-time population is significant to know, cross verify the genetic purity declared in the grow-out test and its subsequent validity with results of the molecular test. This will give us the genetic purity confidence level in crops like pigeon pea since; it is often cross-pollinated with 5-70 per cent natural cross-pollination. This will, however, depend on pollinators, location and environmental factors. Because of nature often cross-pollination some off types may arise in the broader area and population even though the genetic purity declared during the grow-out test is well within the minimum standards. To quantify genetic purity in a larger area with real time population, 'Genetic Purity Confidence Level' (GPCL) based on the statistical regression was developed to understand the data in more extensive area and with a larger population. A seed grower (Mr. Veerashekhar Swamy) in Marched Village, Raichur Taluk and District was selected for the quantification of GPCL for popular variety TS3R. There were no methods reported earlier to know GPCL in field condition, so a this regression model was developed for the variety TS3R can be used at field level.

\section{Introduction}

Pigeon pea (Cajanus cajan (L.) Millsp.) is the only cultivated food crop of the Cajaninae sub-tribe of the family Fabaceae and has a diploid genome with 11 pairs of chromosomes $(2 n=22)$ with genome size estimated to be $858 \mathrm{Mbp}$ (Greilhuber and Obermayer, 1998). This crop occupies an area of $4.65 \mathrm{~m}$. ha (75\% of world area) with an output of $4.78 \mathrm{~m}$. T $(90 \%$ of world production). In India, pigeon pea grown in Maharashtra, Karnataka, Madhya Pradesh,
Andhra Pradesh, Telangana and Gujarat which contribute about 90 per cent of the area and 93 per cent of the production. In India, split cotyledons or dal of pigeon pea are cooked as spicy curry which is eaten with roti (flatbread) and cooked rice. While in Africa and South America both whole dry and immature seeds are used as a vegetable.

In Karnataka, pigeon pea is mainly grown in Gulbarga, Vijayapur, Raichur and Koppal districts contributing to 82 per cent of the total production of state. It is grown on an 
area of about $5.39 \mathrm{~m}$. ha with an output of $4.60 \mathrm{~m}$. T. Being a dry land or rain fed crop it has the productivity of $646 \mathrm{~kg}$ per ha and only 4 per cent of area is under irrigated condition (Anon., 2017). This crop is a most valuable cash crop in semi-arid tropical regions due to its tolerance to drought (Odeny, 2007) and enriches the soil with nitrogen fixation (Rao et al., 1987). Apart from this, it can store well when dried and hence can provide year-round nutritional security. Also, it helps in the alleviation of poverty because of its diverse uses as food, fodder and fuel (Rao et al., 2003). Cultivated pigeon pea is an excellent source of protein (20-22\%), dietary fibre, and various vitamins: magnesium, phosphorus, potassium, copper, and manganese. Some of the wild relatives of pigeon pea such as Cajanus scarabaeoides, $C$. sericeus and $C$. albicans have protein content as high as 32-34 per cent (Saxena et al., 2010).

Pigeon pea is also low in saturated fat, cholesterol, and sodium. This makes pigeon pea, like other legumes a healthy and cheaper substitution for meats and eggs. In combination with grains, pigeon peas constitute well-balanced human nutrition mainly vegetarian diet (Salunkhe et al.,1986 and Ghadge et al.,2008).

There are efforts to develop high yielding and disease resistant varieties looking to the importance of the crop. Though hybrid technology in pigeon pea is on the verge of commercialisation in India, varieties are still more popular in pigeon pea growing areas. Supply of quality seed of these varieties which are genetically pure is very critical to ensure their potential for which they are being developed. The seed produced need to be tested in field grow-out-test (GoT) for genetic purity before it is released for commercial cultivation thus confirming its genuineness and true-to-type characters.
The genetic purity testing is critical in seed production because seed production can result in some undesired pollination events and testing for genetic purity can be an essential component of an effective quality assurance testing program for seed producers. In pigeon pea, foundation class seed need to be tested for genetic purity which mandatory for seed certification but certified class is released with only germination results. This may result in off types during the commercial cultivation of the crop. The farmers notice more off types than the statutory standard and this may contribute to lower yields and outbreak of diseases in the actual cultivation. In an experiment conducted at UAS, Raichur during 2019-20, an effort was made to statistically measure genetic purity at field condition with real time population to find out 'Genetic Purity Confidence Level' (GPCL) for pigeon pea cv.TS3R. This quantification help to find out genetic purity of the certified seed at field level and take measure to rogue out off types to maintain the yield levels.

The need to quantify genetic purity in larger area with real-time population is very important to know and cross verify the genetic purity declared in the grow-out test. This will give us the genetic purity confidence level in crops like pigeon pea since it is often cross-pollinated with 5-70 per cent natural cross-pollination (Saxena et al., 1990). This will however depend on pollinators, location and environmental factors.

Taski-Ajdukovic et al., (2010) opined that one of the main features of high-quality seed is genetic purity which is both same in field and laboratory tests. Genetic impurities in sunflower seed lot can originate due to selfing in large areas of seed production. In sunflower, genetic purity of 18 seed lots of parental lines is controlled by comparative analysis of morphological traits and electrophoretic analysis of 4 isozyme systems, 
according to the UPOV guidelines for DUS test of sunflower lines and hybrids. In 83.3 per cent of samples analyzed, results in field and laboratory were in agreement. In parental line R-8, 5 per cent genetic impurity was found by iso-enzyme analysis, which was not detected based on the morphological characteristics. While electrophoretic analysis of samples L-10 and L-11 showed less genetic impurities in comparison with the analysis in the field.

\section{Materials and Methods}

The need to quantify genetic purity in a larger area with real-time population is significant to know, cross verify the genetic purity declared in the grow-out test and its subsequent validity with results of the molecular test. To know the 'Genetic Purity Confidence Level' (GPCL) we have developed a procedure to understand the data in more extensive area and with a larger population. There were no methods reported earlier to know GPCL in field condition, so a linear regression model was developed for the variety TS3R.

\section{Selection of variety}

In pigeon pea, popular variety TS3R was selected to quantify 'Genetic Purity Confidence Level' (GPCL). This improved variety grown in the Marched village of Raichur district (Farmer name: $\mathrm{Mr}$ Veerashekar Swamy) and have a duration of 150 days. This variety also resistant to wilt and high yielding (12.5-20 q/acre) compared to other local varieties of the region.

\section{Simple regression}

It is defined as the value of the dependent variable is estimated by only one independent variable, or it refers to the prediction of the dependent variable (Y) based on an independent variable $(\mathrm{X})$. It varies between - $\infty$ and $+\infty$. The dependent variable (Y) here is the genetic purity at field level and independent variable $(\mathrm{X})$ is plant population.

\section{Farmer Name and area}

Mr. Veerashekhar Swamy (Marched Village, Raichur Taluk / District) and area considered is one hectare.

\section{Plant Population per hectare}

The plant population of the pigeon pea $\mathrm{Cv}$. TS3R is calculated on the actual basis by counting number of plants in each row. The desired population per hectare was calculated as per the formula (taking the spacing as $90 \mathrm{x}$ $60 \mathrm{~cm})$ :

Plant Population =

$10000 \mathrm{~m}^{2}$ X Number of Seeds per Stand

Product of Spacing $\left(\mathrm{m}^{2}\right)$

\section{Procedure to measure GPCL at field level}

The unit area is taken as one hectare and plant populations are counted row-wise. The one hectare land is divided into 15 rows with an identification mark and numbers of plants are calculated in each row. Each of the plants in a row is examined for the characters described by the breeder and number of off-types is noted.

The genetic purity of each of the row was calculated and indicated for regression analysis using MS-Excel. Based on the data simple regression was calculated to predict the GPCL for the pigeon pea variety-TS3R using the equation: $Y=\alpha+\beta X+\varepsilon$

\section{Wherea}

$\mathrm{Y}=$ represent dependant variable (genetic purity) along the ' $\mathrm{Y}$ ' axis

$\mathrm{X}=$ represent independent variable (plant population) along the ' $\mathrm{X}$-axis 
$\alpha=$ (alpha) represent constant known as intercept-equals to ' $\mathrm{Y}$ ' (when $\mathrm{X}=0$ )

$\beta=$ (beta) represent constant known as regression co-efficient (how much

'Changes for a unit change in ' $\mathrm{X}$ ')

$\varepsilon=$ the error term; the error in predicting the value of ' $Y$ ', given the value of ' $X$.'

\section{Results and Discussion}

The desired plant population per hectare as per the formula is calculated as 18518. The actual or real time population per hectare: 14284 after the loss in population due to germination and loss due to some natural causes like low vigour, improper planting method etc. No. of rows divided in to 15 . The results of simple linear regression analysis were furnished in Table 1. The results indicate that, all the rows having different plant population are arranged in ascending order showing difference in the genetic purity based on the characters followed for field grow-out test. The dependant variable (genetic purity $\%$-Y) varies with population per row (independent variable-X). For every increase (by one plant) of plant population the genetic purity percentage decreased by 0.006 per cent even though the values of this is nonsignificant. This gives a negative regression relationship between dependant and independent variables.

Table.1 Linear regression model to measure genetic purity confidence level in pigeon pea cv. TS3R

\begin{tabular}{|c|c|c|}
\hline \multirow[t]{2}{*}{ Rows } & Genetic Purity \% & Population per row \\
\hline & Y (Dependant) & $\mathrm{X}$ (Independent) \\
\hline 1 & 98.50 & 688 \\
\hline 2 & 98.20 & 724 \\
\hline 3 & 97.94 & 868 \\
\hline 4 & 98.99 & 895 \\
\hline 5 & 92.50 & 900 \\
\hline 6 & 97.71 & 920 \\
\hline 7 & 96.32 & 924 \\
\hline 8 & 97.34 & 927 \\
\hline 9 & 97.50 & 960 \\
\hline 10 & 94.72 & 1056 \\
\hline 11 & 95.56 & 1068 \\
\hline 12 & 98.50 & 1080 \\
\hline 13 & 96.30 & 1082 \\
\hline 14 & 96.70 & 1092 \\
\hline 15 & 94.60 & 1100 \\
\hline \multicolumn{2}{|c|}{$\begin{array}{l}\text { R Square (Co-efficient of } \\
\text { determination) }\end{array}$} & 0.17 \\
\hline \multicolumn{2}{|c|}{ Standard Error } & 1.70 \\
\hline \multicolumn{2}{|c|}{ Significance F } & 0.13 \\
\hline \multicolumn{2}{|c|}{ Intercept } & 102.14 \\
\hline \multicolumn{2}{|c|}{ Independent Variable } & -0.006 \\
\hline \multicolumn{2}{|c|}{$\begin{array}{l}\text { Regression relation } \\
(\mathbf{Y}=\boldsymbol{\alpha}+\boldsymbol{\beta} \mathbf{X}+\boldsymbol{\varepsilon})\end{array}$} & $\begin{array}{l}Y=102.14+(-0.006) X \\
\text { Plants per hectare }\end{array}$ \\
\hline
\end{tabular}


The Co-efficient of determination $\left(\mathrm{R}^{2}\right)$ indicates that as much as $17 \%$ of total variation in genetic purity depends on the plant population. So the Genetic Purity Confidence Level (GPCL) is calculated as 0.006 per cent decrease for increase in every plant in each row. This hypothesis is explained with a case study as follows:

\section{Case study to test this relationship}

i) Let the No. of plants in one ha. of land: 15698 (with declared genetic purity of $98 \%$ for certified class).

ii) Calculated with the formula the genetic purity confidence can be calculated by $\mathrm{Y}=102.14+(-0.006) \mathrm{X}$ Plants per hectare. $\mathrm{Y}=102.14+(-0.006) \mathrm{X} 15698$ gives negative regression of 7.952 and this value need to be deducted from the maximum genetic purity for this class of seed possible which is $100 \%$.

iii) Deduct the GPCL value given in (ii) with $100 \%$ and the genetic purity confidence level for this case (100-7.952) is $92.048 \%$ though it is declared as $98 \%$ in the field grow-out test.

The need to quantify genetic purity in a larger area with real-time population is significant to know, cross verify the genetic purity declared in the grow-out test and its subsequent validity with results of the molecular test. This will give us the genetic purity confidence level.

There were no methods reported earlier to know GPCL in field condition, so a linear regression model was developed for the variety TS3R only and this can be applied to all the cultivated varieties of pigeon pea. Similar methods were developed by TaskiAjdukovic et al., (2010) who opined genetic impurities in sunflower seed lot can originate due to selfing in large areas of seed production.
Based on the results it is empirical to conclude that the genetic purity varies with plant population in case of pigeon pea which is often cross pollinated by the formula $\mathrm{Y}=102.14+(-0.006) \mathrm{X}$ Plants per hectare. This relationship can be used to calculate the Genetic Purity Confidence Level for the variety TS3R in larger area. This formula gives actual genetic purity percentage at field level helps in scheduling of rouging activities and reinforcing the gap filling for the lost population. Also this relationship helps in calculation of proper yield estimations and income per unit area.

\section{References}

Anonymous, 2017, www.dacnet.nic.in/ean. Agricultural Statistics at a Glance2016.

Ghadge,P.N., Shewalkar, S.V. and Wankhede, D.B., 2008. Effect of Processing Methods on Qualities of Instant Whole Legume: Pigeon Pea (Cajanus cajan L.). Agricultural Engineering International: CIGR EJournal. 10 (online).

Greilhuber, R., Obermayer, J., 1998. Genome size variation in Cajanus cajan (Fabaceae): A reconsideration. Plant Systematics and Evolution. 212(12): 135

Odeny, D. A., Jayashree, B., Ferguson, M., Hoisington, D., Cry, L. J., and Gebhardt, C. 2007. Development, characterization and utilization of microsatellite markers in pigeon pea. Plant Breeding. 126: 130-136

Rao, J.V.D.K.K., Thompson, J.A., Sastry, P.V.S.S., 1987, 101: 107. Measurement of N2-fixation in field-grown pigeon pea [Cajanus cajan (L.) Millsp.] using 15N-labelled fertilizer. Plant and Soil. 101: 107.

Rao, S.C., Phillips, W.A., Mayeux, H.S. and Phatak, S.C. 2003. Potential rain and 
forage production of early maturing pigeon pea in the southern Great Plains. Crop Science., 43:2212-2217.

Salunkhe, D. K. Chavan, J. K. Kadam S. S. and Reddy. N. R., 1986. Pigeon pea as an important food source. Critical Reviews in Food Science and Nutrition. 23(2): 212-214

Saxena, K. B., Singh, L. and Gupta, M. D., 1990. Variation for natural out-crossing in pigeon pea. Euphytica. 46: 143-148.

Saxena, R. K., Prathima, C., Saxena, K. B.,
Hoisington, D. A., Singh, N. K and Varshney, R. K., 2010, Novel SSR markers for polymorphism detection in pigeon pea (Cajanus spp.). Plant Breeding. 129 (2): 142-148.

Taski-Ajdukovic, Radic, V., Jevtic, A., Canak, P., Vujakovic, M., Miklic, V. 2010, Comparative analysis of laboratory and field procedures for testing purity of sunflower parental lines. Field and Vegetable Crops Research. 47(1): 153-156.

\section{How to cite this article:}

Rakesh C. Mathad and Channaveeraswamy, A. S. 2020. Statistical Measure to Quantify Genetic Purity in a Larger Area with Real-Time Population in Pigeon Pea. Int.J.Curr.Microbiol.App.Sci. 9(09): 2469-2474. doi: https://doi.org/10.20546/ijcmas.2020.909.308 